\title{
Factors associated with distant recurrence following R0 lobectomy for pNO lung adenocarcinoma
}

\author{
Whitney S. Brandt, MD, ${ }^{a}$ Ilies Bouabdallah, MD, ${ }^{a}$ Kay See Tan, PhD, ${ }^{\mathrm{b}}$ Bernard J. Park, MD, ${ }^{\mathrm{a}}$ \\ Prasad S. Adusumilli, MD, ${ }^{\text {a }}$ Daniela Molena, MD, ${ }^{a}$ Manjit S. Bains, MD, ${ }^{a}$ James Huang, MD, \\ James M. Isbell, MD, ${ }^{\mathrm{a}}$ Matthew J. Bott, MD, ${ }^{\mathrm{a}}$ and David R. Jones, $\mathrm{MD}^{\mathrm{a}}$
}

\section{ABSTRACT}

Objective: We investigated factors associated with distant recurrence, diseasefree survival (DFS), and overall survival (OS) following R0 lobectomy for pathologic node-negative (pN0) lung adenocarcinoma.

Methods: We performed a retrospective analysis of a prospectively maintained
database of patients with pT1-3NOM0 non-small cell lung cancer. Exclusion
criteria included metachronous lung cancer, sublobar/incomplete resection, non-
adenocarcinoma histology, and induction/adjuvant therapy. The primary outcome
was distant recurrence; secondary outcomes were DFS and OS. Associations be-
tween variables and outcomes were assessed by Fine-Gray competing-risk regres-
sion for distant recurrence and Cox proportional hazard models for DFS and OS.

Results: Of 2392 patients identified with pT1-3N0M0 lung adenocarcinoma, 893 met the inclusion criteria. Median follow-up was 35.0 months (range, 0.1202 months). Thirteen percent of patients developed recurrence $(n=115)$, of which $86 \%(n=99)$ were distant. The 5-year cumulative incidence of distant recurrence was 14\% (95\% confidence interval [CI], 11\%-17\%). On multivariable analysis, pT2a (hazard ratio [HR], 2.84; 95\% CI, 1.56-5.16; $P=.001$ ) and pT2b/3 (HR, 6.53; 95\% CI, 3.17-13.5; $P<.001)$ tumors were associated with distant recurrence. Recent surgery was associated with decreased distant recurrence $(\mathrm{HR}, 0.43 ; 95 \% \mathrm{CI}, 0.20-0.91 ; P=.028)$, and lymphovascular invasion was strongly associated with distant recurrence (HR, 1.62; 95\% CI, 1.00-2.63; $P=.05)$. DFS was independently associated with pT stage $(P<.001)$ and lymphovascular invasion $(P=.004)$.

Conclusions: In patients undergoing R0 lobectomy with pN0 lung adenocarcinoma, pT stage and lymphovascular invasion were associated with distant recurrence and decreased DFS. These observations support the inclusion of these patients in future clinical trials investigating adjuvant targeted and immunotherapies. (J Thorac Cardiovasc Surg 2018;155:1212-24)

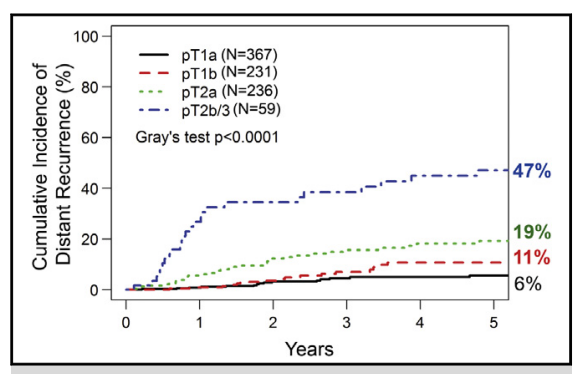

Cumulative incidence of distant recurrence by pathologic $T(p T)$ stage $(n=893)$.

\section{Central Message}

In patients with pNO lung adenocarcinoma treated with R0 lobectomy, pathologic T stage (pT) and lymphovascular invasion are associated with distant recurrence and decreased survival.

\section{Perspective}

Factors associated with distant recurrence following R0 lobectomy for node-negative lung adenocarcinoma have not been well studied. We sought to identify factors associated with distant recurrence and disease-free survival in patients with early-stage lung adenocarcinoma to better identify patients who may benefit from adjuvant targeted or immunotherapies.

See Editorial Commentary page 1225 .

See Editorial page 1205.
From the ${ }^{\mathrm{a}}$ Thoracic Surgery Service and ${ }^{\mathrm{b}}$ Department of Biostatistics, Memorial Sloan Kettering Cancer Center, New York, NY.

This work was supported by National Institutes of Health Grants R01 CA136705 (to D.R.J.) and T32 CA009501 (to W.S.B.). This work was also supported in part by National Institutes of Health, National Cancer Institute Cancer Center Support Grant P30 CA008748.

Drs Brandt and Bouabdallah contributed equally to this work.

Received for publication May 16, 2017; revisions received Sept 5, 2017; accepted for publication Sept 18, 2017; available ahead of print Dec 13, 2017.

Address for reprints: David R. Jones, MD, Thoracic Surgery Service, Memorial Sloan Kettering Cancer Center, 1275 York Ave, Box 7, New York, NY 10065 (E-mail: jonesd2@mskcc.org).

$0022-5223 / \$ 36.00$

Copyright (c) 2017 by The American Association for Thoracic Surgery

https://doi.org/10.1016/j.jtcvs.2017.09.151
Five-year overall survival (OS) is $66 \%$ to $82 \%$ for patients with surgically resected stage I non-small cell lung cancer (NSCLC) and $47 \%$ to $52 \%$ for patients with stage II NSCLC. ${ }^{1}$ The primary contributing factor in decreased

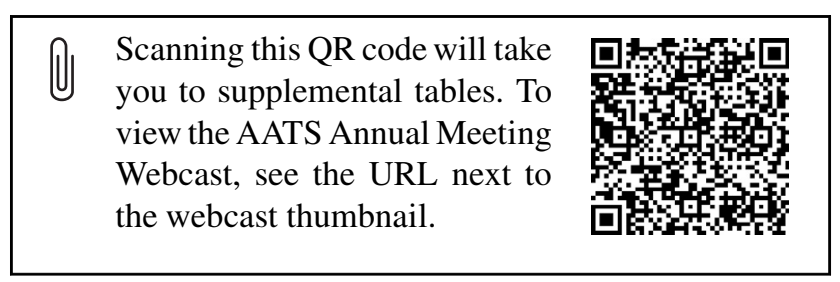




\begin{tabular}{|c|c|}
\hline \multicolumn{2}{|c|}{ Abbreviations and Acronyms } \\
\hline CALGB & $=$ Cancer and Leukemia Group B \\
\hline $\mathrm{CI}$ & $=$ confidence interval \\
\hline CIR-any & $\begin{array}{l}=\text { cumulative incidence of any } \\
\text { recurrence }\end{array}$ \\
\hline \multicolumn{2}{|c|}{$\begin{aligned} \text { CIR-distant }= & \text { cumulative incidence of distant } \\
& \text { recurrence }\end{aligned}$} \\
\hline CT & $=$ computed tomography \\
\hline DFS & $=$ disease-free survival \\
\hline DLCO & $\begin{aligned}= & \text { diffusion capacity of the lung for } \\
& \text { carbon monoxide }\end{aligned}$ \\
\hline $\mathrm{FEV}_{1}$ & $=$ forced expiratory volume in 1 second \\
\hline HR & $=$ hazard ratio \\
\hline LR & $=$ locoregional recurrence \\
\hline LVI & $=$ lymphovascular invasion \\
\hline $\mathrm{NCCN}$ & $\begin{aligned}= & \text { National Comprehensive Cancer } \\
& \text { Network }\end{aligned}$ \\
\hline NSCLC & $=$ non-small cell lung cancer \\
\hline OS & $=$ overall survival \\
\hline PET & $=$ positron emission tomography \\
\hline pNo & $=$ pathologic node-negative \\
\hline pT & $=$ pathologic tumor \\
\hline $\mathrm{SUV}_{\mathrm{m}}$ & $=$ maximum standardized uptake value \\
\hline
\end{tabular}

survival is recurrence; 3 -year disease-free survival (DFS) is $77 \%$ to $86 \%$ for all stages of NSCLC. ${ }^{2}$ It is widely accepted that complete resection (R0) offers improved survival over $\mathrm{R} 1$ or R2 resection. In patients with stage I NSCLC, 5-year OS increases from $37 \%$ for patients with $\mathrm{R} 1$ resection to $62 \%$ for those with R0 resection. ${ }^{3}$ For patients with stage II NSCLC, OS increases from $29 \%$ for patients with R1 resection to $41 \%$ for those with R0 resection. ${ }^{3}$ In addition, the results of the Lung Cancer Study Group trial support lobectomy over sublobar resection as the preferred extent of resection, even for peripheral T1N0 lesions. ${ }^{4}$ In that study, local recurrence rates were 3 -fold higher for patients who underwent sublobar resection, although distant recurrence rates were the same. ${ }^{5,6}$

There is a surprising lack of information regarding the incidence of distant recurrence-the primary driver of both DFS and OS-following R0 lobectomy for pathologic node-negative ( $\mathrm{pN} 0)$ disease. Moreover, evidence-based predictors of development of distant recurrence may support the inclusion of patients with these characteristics in future randomized trials designed to evaluate the role of adjuvant therapies in the treatment of early-stage node-negative lung cancer. To address this knowledge gap, we analyzed clinicopathologic and tumor genomic features associated with distant recurrence, any recurrence, DFS, and OS in a highly curated group of patients who underwent $\mathrm{R} 0$ lobectomy for $\mathrm{pNO}$ lung adenocarcinoma.

\section{METHODS \\ Patient Characteristics}

On approval of this study from our Institutional Review Board, we performed a retrospective analysis of our institution's prospectively maintained database for patients diagnosed with pT1-3NOM0 NSCLC who underwent surgical resection between January 2000 and March 2016. All patients underwent surgery with curative intent. Exclusion criteria included sublobar resection, non-adenocarcinoma histologic subtype, R1 or R2 resection, treatment with any induction or adjuvant therapy, synchronous lung primaries that recurred or were treated nonsurgically, or metachronous lung cancer. Metachronous lung cancers were distinguished from recurrent lesions using criteria established by Martini and Melamed ${ }^{7}$ and molecular testing, when available.

Patient demographic characteristics, forced expiratory volume in $1 \mathrm{sec}-$ ond $\left(\mathrm{FEV}_{1}\right)$, diffusion capacity of the lung for carbon monoxide (DLCO), primary tumor maximum standardized uptake value $\left(\mathrm{SUV}_{\max }\right)$, tumor pathology (American Joint Committee on Cancer, 7th edition), and tumor genomic data (EGFR and KRAS) were recorded. A positive EGFR mutation was classified as an activating EGFR mutation (ie, exon 19 deletion or exon $21 \mathrm{~L} 858 \mathrm{R}$ mutation). KRAS mutations were defined as present or absent.

\section{Follow-up}

Information on patient follow-up was extracted from the medical record and included medical history, physical examination, and chest computed tomography (CT) every 6 months for 2 to 3 years and then annually, in accordance with the National Comprehensive Cancer Network (NCCN) guidelines. ${ }^{8}$ The date of the last follow-up was noted, as well as the date of death, if applicable.

For patients who experienced recurrence, the first site of recurrence was classified as either distant, locoregional, or both. Locoregional recurrence (LR) was defined as a relapse in the surgical margin or bronchus staple line or involvement of the ipsilateral mediastinal and/or ipsilateral hilar lymph nodes. ${ }^{9,10}$ Distant recurrence included all locations outside of LR and included supraclavicular nodes, contralateral mediastinal or hilar nodes, another lobe in the ipsilateral lung, or any tissue or organ outside of the LR zone. Simultaneous LR and distant recurrence was classified as distant recurrence. Recurrence was identified radiographically (positron emission tomography [PET] or CT) and/or by pathologic confirmation.

\section{Pathologic Evaluation}

Tumors were classified according to the predominant histologic subtype, in accordance with the International Association for the Study of Lung Cancer/American Thoracic Society/European Respiratory Society guidelines, into lepidic (including adenocarcinoma in situ), acinar, papillary, micropapillary, solid, or other (including minimally invasive adenocarcinoma and colloid subtypes). ${ }^{11}$

\section{Statistical Analyses}

Patient demographic and clinical characteristics were summarized with descriptive statistics. Of the 893 patients included, $2(0.2 \%)$ had missing pleural invasion status, $15(1.6 \%)$ had missing lymphovascular invasion (LVI) status, $128(14 \%)$ had missing histologic subtype, $21(2.3 \%)$ had missing $\mathrm{FEV}_{1}, 330$ (37\%) had missing EGFR mutation status, 481 (54\%) had missing KRAS mutation status, and 172 (19\%) had missing primary tumor $\mathrm{SUV}_{\max }$ data. Covariates, including outcome measures, were used in the imputation of missing data. Variables included in the multiple imputation models were age at surgery, sex, pulmonary comorbidity, cardiac comorbidity, year of surgery (divided into tertiles: 2000-2006, 20072013, 2014-2016), primary tumor $\mathrm{SUV}_{\max }, \mathrm{FEV}_{1}$, DLCO, tumor size, tumor histologic subtype, LVI, pleural invasion, and pathologic tumor (pT) stage. EGFR and KRAS were not included in the imputation procedure due to excessive missing data points. Based on the recommendation from 
van der Kruijk, ${ }^{12}$ we included the log of duration from surgery to any recurrence (and death without recurrence) or last follow-up, which is available for all patients. ${ }^{12}$

Five different imputed data sets were created by predictive mean matching using the aregimpute imputation routine in R 3.1.1. (R Development Core Team, Vienna, Austria). Analyses of the survival endpoints were applied to each imputed data set, which were then combined across the data sets using the Rubin rule to obtain overall estimates of each regression coefficient and variance. ${ }^{13}$ Year of surgery (included in models as tertiles) is an adjustment factor/surrogate for potential changes in clinical practice, especially nonsurgical therapies.

The primary endpoint was cumulative incidence of distant recurrence (CIR-distant). Secondary endpoints were cumulative incidence of any recurrence (CIR-any), DFS, and OS. All survival endpoints were estimated from the time of surgery and censored on the date of the last follow-up. Associations between variables and recurrence were analyzed using the competing risk method. For CIR-distant, independent LR and death without any recurrence were considered competing events; for CIR-any, death without any recurrence was the competing event. Differences in CIR-distant and CIR-any between groups were assessed using Gray's test. ${ }^{14}$ Associations between variables and hazard of recurrence (distant or any) were estimated using the Fine and Gray competing risk model. ${ }^{15}$ Multivariable models were constructed by starting with variables with $P<.10$ in univariable analyses, keeping age at surgery in the model. Visceral pleural invasion and tumor size were not included in the multivariable model secondary to possible collinearity with pT. All $P$ values were 2-tailed, and $P<.05$ was considered statistically significant. DFS was defined from the time of surgery to the time of death or recurrence, and OS was defined from the time of surgery to the time of death; both were estimated using the Kaplan-Meier method and compared between groups using the log-rank test. The nonlinear relationship between tumor size and distant recurrence (and other time-to-event endpoints) were assessed using restricted cubic splines. ${ }^{16}$ Goodness of fit was assessed based on modified weighted Schoenfeld residuals to test the proportionality of subdistribution hazards for the Fine-Gray model, appropriate for outcomes with competing risks. ${ }^{16}$ We examined various functional forms of time including linear, quadratic, and log. Analyses were conducted in R 3.1.1 (R Development Core Team, Vienna, Austria) using the cmprsk package and Stata 13 (StataCorp, College Station, Tex).

\section{RESULTS \\ Patient Population}

In total, 2392 patients with pT1-3NOM0 NSCLC underwent surgical resection from January 2000 to March 2016. Of these, 893 met the inclusion criteria and were included in the study (Figure 1).

Patient clinicopathologic features are summarized in Table 1. Median follow-up was 35.0 months (range, 0.1202 months). At the conclusion of our analysis, 638 patients $(71 \%)$ remained alive without recurrence (Table 2). Twenty-seven patients $(3 \%)$ had no additional follow-up beyond 90 days after their surgery. Among the entire cohort, $13 \%$ of patients developed recurrence $(n=115), 86 \%$ of which were pathologically confirmed. In patients with isolated pulmonary recurrence, $19 \%$ ( 8 of 42 ) had molecular testing that supported recurrent disease. Most recurrences were distant $(\mathrm{n}=99)$. The most common sites of DR were lung $(n=42)$, brain $(n=22)$, and bone $(n=19)$

\section{2 patients with pT1-3NOMO NSCLC}

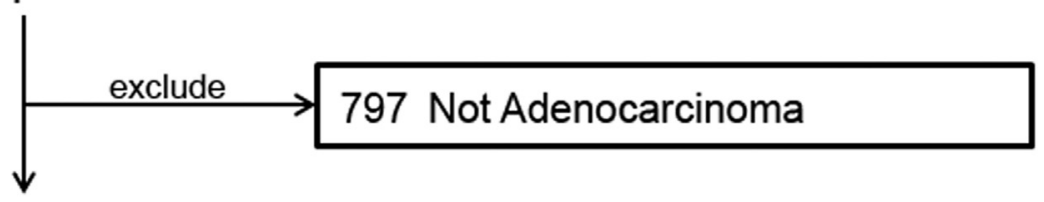

1595 pT1-3NOMO Adenocarcinoma

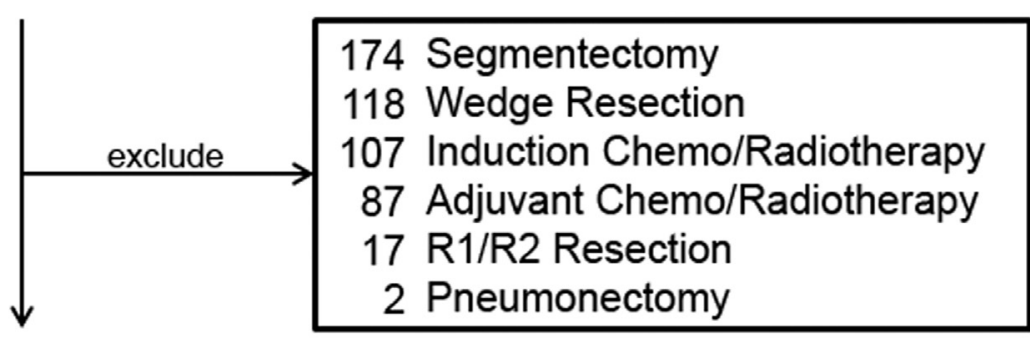

1090 pT1-3N0M0 R0 Lobectomy

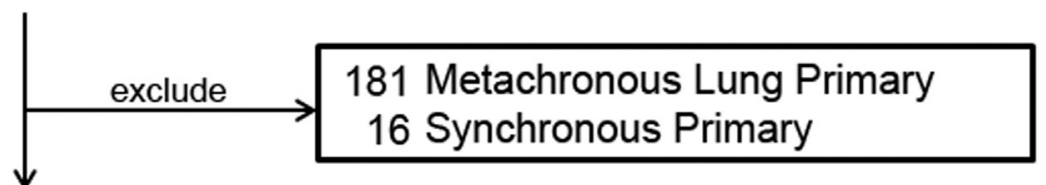

\section{Patients}

FIGURE 1. CONSORT flow diagram. Original population and exclusion criteria used to determine the final cohort of patients. NSCLC, Non-small cell lung cancer; $p T$, pathologic tumor. 
TABLE 1. Clinicopathologic characteristics of the pT1-3N0M0 lung adenocarcinoma cohort $(n=893)$

\begin{tabular}{|c|c|}
\hline Characteristic & Value \\
\hline Age, y, median (range) & $72(36-92)$ \\
\hline \multicolumn{2}{|l|}{$\operatorname{Sex}, \mathrm{n}(\%)$} \\
\hline Female & $559(63)$ \\
\hline Male & $334(37)$ \\
\hline \multicolumn{2}{|l|}{ Comorbidities, n (\%) } \\
\hline Pulmonary & $220(25)$ \\
\hline Cardiac & $492(55)$ \\
\hline \multicolumn{2}{|l|}{ Pulmonary function tests, median (range) } \\
\hline $\mathrm{FEV}_{1}, \%(\mathrm{n}=872)$ & $94(26-408)$ \\
\hline Diffusion, $\%(\mathrm{n}=799)$ & $84.0(24-165)$ \\
\hline \multicolumn{2}{|l|}{ Time of surgery (tertile), n (\%) } \\
\hline $2000-2006$ & $313(35)$ \\
\hline $2007-2013$ & $306(34)$ \\
\hline 2014-2016 & $274(31)$ \\
\hline \multicolumn{2}{|l|}{ Tumor characteristics, median (range) } \\
\hline Tumor $\operatorname{SUV}_{\max }(\mathrm{n}=721)$ & $3.4(0.5-9.8)$ \\
\hline Tumor size $(\mathrm{cm})$ & $2.2(0.2-9.0)$ \\
\hline \multicolumn{2}{|c|}{ Predominant histologic subtype $(\mathrm{n}=765), \mathrm{n}(\%)$} \\
\hline Lepidic & $113(15)$ \\
\hline Acinar & $361(47)$ \\
\hline Papillary & $144(19)$ \\
\hline Micropapillary & $27(3.5)$ \\
\hline Solid & $109(14)$ \\
\hline Other & $11(1.4)$ \\
\hline \multicolumn{2}{|l|}{ Invasion, $\mathrm{n}(\%)$} \\
\hline Visceral pleural invasion $(\mathrm{n}=891)$ & $118(13)$ \\
\hline Vascular invasion $(\mathrm{n}=878)$ & $273(31)$ \\
\hline \multicolumn{2}{|l|}{ Pathologic tumor stage (pT), n (\%) } \\
\hline 1a & $367(41)$ \\
\hline $1 b$ & $231(26)$ \\
\hline $2 \mathrm{a}$ & $236(26)$ \\
\hline $2 b / 3$ & $52(6.1)$ \\
\hline \multicolumn{2}{|l|}{ Driver mutation, $\mathrm{n}(\%)$} \\
\hline$E G F R(\mathrm{n}=563)$ & $108(19)$ \\
\hline$K R A S(\mathrm{n}=412)$ & $140(34)$ \\
\hline
\end{tabular}

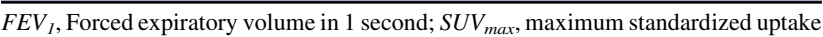
value; $p T$, pathologic tumor.

(Table 2). The median disease-free interval for all patients who developed any recurrence was 21.3 months (range, 0.9-176 months). The median disease-free interval was 26.9 months (range, 2.5-176 months) for pT1a tumors, 28.4 months (range, 7-130 months) for pT1b tumors, 20.5 months (range, 0.9-82 months) for pT2a tumors, and 10.8 months (range, 1.3-57 months) for pT2b/3 tumors. Of the 115 patients who experienced recurrence, 85 $(74 \%)$ died (median time to death after recurrence, 18.6 months; range, 0.3-151 months). Of the 99 patients with distant recurrence, $76(77 \%)$ died (median time to death, 15.4 months; range, $0.3-151$ months). Of the 16 patients with isolated LR, $9(56 \%)$ died (median time to death,
45 months; range, 11.4-107 months). Of these 9 patients with isolated LR who died, the cause of death was distant disease $(n=2)$, local disease $(n=2)$, and unknown $(\mathrm{n}=5)$. Isolated LRs were treated with radiation $(\mathrm{n}=6)$, concurrent chemoradiotherapy $(\mathrm{n}=4)$, surveillance $(\mathrm{n}=2)$, re-resection $(\mathrm{n}=2)$, or unknown $(\mathrm{n}=2)$.

\section{Distant Recurrence}

The 5-year CIR-distant for the entire cohort was 14\% (95\% CI, 11\%-17\%) (Figure 2, A). When stratified by pT stage, the 5-year CIR-distant was 6\% $(95 \%$ CI, 3\%$9 \%)$ for pT1a tumors, $11 \%(95 \%$ CI, 7\%-18\%) for pT $1 \mathrm{~b}$ tumors, $19 \%$ (95\% CI, 14\%-26\%) for pT2a tumors, and $47 \%$ (95\% CI, 35\%-63\%) for pT2b/3 tumors $(P<.001)$ (Figure 2, B). The 5-year CIR-distant was $11 \%(95 \% \mathrm{CI}$, $8 \%-14 \%)$ for patients without LVI versus $20 \%(95 \% \mathrm{CI}$, $15 \%-27 \%$ ) for those with LVI (Figure 2, $C$ ). To determine factors associated with distant recurrence, we performed an initial univariable analysis using competing-risk regression (Table 3). As expected, several tumor features $\left(\mathrm{SUV}_{\text {max }}\right.$, tumor size, pT stage, histologic subtype, and LVI) were significantly associated with the development of distant recurrence. Surgery in the more recent 2 tertiles was also associated with decreased distant recurrence (2007-2013: HR, 0.64; 95\% CI, 0.41-0.99, $P=.045 ; 2014-2016$ : HR, $0.43 ; 95 \%$ CI, $0.20-0.91 ; P=.028)$. Neither EGFR nor $K R A S$ mutation was associated with distant recurrence. There was no evidence of a nonlinear relationship between age of surgery $(P=.095)$ and tumor size $(P=.093)$ with respect to distant recurrence. On multivariable analysis, pT2a tumor, pT2b/3 tumor (more likely), and tertile of surgery (2014-2016; less likely) were associated with distant recurrence. LVI had a strong correlation with distant recurrence $(P=.05)$. Primary tumor $\mathrm{SUV}_{\max }$ and histologic subtype, including solid and micropapillary subtypes, were not significant in the multivariable model. Based on the proposed method by Zhou and colleagues, ${ }^{16,17}$ the goodnessof-fit test did not detect any significant violation of the proportionality assumption among the variables in the final multivariable competing-risk regression models for distant recurrence. A multivariable competing-risk regression model based on complete cases was also performed. Characteristics of the complete case population are reported in Table E1. Results from complete-case multivariable analysis of recurrence are reported in Table E2 for reference, although estimates should be interpreted with caution owing to a smaller sample size and lower event number.

\section{Other Recurrences}

Of the 893 patients included in the study, 16 developed isolated LR ( $1.8 \%$ of the entire cohort). Of the 367 patients with pT1a tumors, $3(0.8 \%)$ developed isolated LR; in comparison, 4 of $231(1.7 \%)$ with pT1b tumors, 6 of $236(2.5 \%)$ with pT2a tumors, and 3 of $59(5.1 \%)$ with pT2b/3 tumors 
TABLE 2. Sites of recurrence $(n=893)$

\begin{tabular}{lcc}
\hline \multicolumn{1}{c}{ Factor } & $\begin{array}{c}\text { All patients } \\
(\mathbf{n}=\mathbf{8 9 3}), \mathbf{n}(\%)\end{array}$ & $\begin{array}{c}\text { Patients with } \\
\text { recurrence } \\
(\mathbf{n}=\mathbf{1 1 5}), \mathbf{n}(\%)\end{array}$ \\
\hline $\begin{array}{l}\text { Recurrence site, } \mathrm{n}(\%) \\
\text { None }\end{array}$ & $638(71)$ & - \\
Death without recurrence & $140(16)$ & - \\
Locoregional only & $16(1.8)$ & $16(14)$ \\
Distant & $99(11)$ & $99(86)$ \\
Brain & $22(2.5)$ & $22(19)$ \\
Lung or pleura & $42(4.7)$ & $42(37)$ \\
Bone & $19(2.1)$ & $19(17)$ \\
Adrenal & $6(0.7)$ & $6(5.2)$ \\
Liver & $4(0.4)$ & $4(3.5)$ \\
Other & $6(0.7)$ & $6(5.2)$ \\
Multisite recurrence, $\mathrm{n}(\%)$ & & \\
No & $90(10)$ & $90(78)$ \\
Yes & $25(2.8)$ & $25(22)$ \\
\hline
\end{tabular}

developed isolated LR. The CIR-any was $16 \%(95 \%$ CI, $13 \%-19 \%)$ for the entire cohort, $6 \%(95 \%$ CI, $4 \%-10 \%)$ for pT1a tumors, $14 \%(95 \% \mathrm{CI}, 9 \%-21 \%)$ for pT $1 \mathrm{~b}$ tumors, $24 \%$ (95\% CI, 18\%-31\%) for pT2a tumors, and $53 \%(95 \%$ CI, $41 \%-69 \%)$ for pT2b/3 tumors. As expected, variables associated with any recurrence on univariable analysis were largely the same as those associated with distant recurrence; these included primary tumor $\mathrm{SUV}_{\max }$, tumor size, $\mathrm{pT} 1 \mathrm{~b}, \mathrm{pT} 2 \mathrm{a}, \mathrm{pT} 2 \mathrm{~b} / 3$, surgery in more recent tertiles, histologic subtype, visceral pleural invasion, and LVI (Table E3). There was no evidence of nonlinear relationship between tertile of surgery $(P=.286)$ and tumor size $(P=.070)$ with respect to any recurrence. On multivariable analysis, the same variables associated with distant recurrence remained associated with any recurrence (surgery in the most recent tertile [decreased risk] and lymphovascular invasion, pT2a, and pT2b/3 [increased risk]) (Table E3). The goodness-of-fit test did not detect significant violation of the proportionality assumption among the variables in the final multivariable competing-risk regression models for any recurrence.

\section{DFS and OS}

The 5-year DFS for the entire cohort was 72\% $(95 \%$ CI, $68 \%-76 \%$ ), and 5-year OS for the entire cohort was $78 \%$ $(95 \%$ CI, $74 \%-82 \%)$. The 5-year DFS was $84 \%(95 \%$ CI, $79 \%-89 \%)$ for pT1a tumors, $73 \%(95 \%$ CI, $66 \%$ $82 \%$ ) for pT 1 b tumors, $63 \%(95 \%$ CI, $55 \%-71 \%)$ for pT2a tumors, and 35\% (95\% CI, 24\%-51\%) for pT $2 \mathrm{~b} / 3$ tumors $(P<.001)$ (Figure 3, $A$ ). The 5-year OS was $86 \%$ (95\% CI, $82 \%-91 \%)$ for pT1a tumors, $76 \%(95 \%$ CI, $69 \%-85 \%)$ for pT1b tumors, $73 \%$ (95\% CI, 66\%-81\%) for pT2a tumors, and 56\% (95\% CI, 43\%-72\%) for pT2b/3 tumors $(P<.001)$ (Figure 3, B). The 5-year DFS was $62 \%(95 \% \mathrm{CI}, 54 \%-70 \%)$ for patients with LVI versus
$76 \%(95 \%$ CI, $72 \%-81 \%)$ for patients without LVI $(P=.004)$ (Figure $4, A)$. The 5-year OS was $69 \%(95 \%$ CI, $61 \%-77 \%)$ for patients with LVI versus $81 \%(95 \%$ CI, $77 \%-85 \%)$ for patients without LVI $(P=.105)$ (Figure 4, B).

\section{DISCUSSION}

There is a paucity of data on predictors of distant recurrence - the major driver of decreased DFS and OS-for early-stage lung cancer. Our study is unique in that it focuses on patients with lung adenocarcinoma who have had optimal surgical treatment (lobectomy and R0 resection) and node-negative disease (pN0) and thus should have a relatively low risk of developing distant recurrence. Interestingly, even in this select cohort, the overall 5-year CIR-distant was $14 \%$, which increased to $47 \%$ for T2b/3 tumors. We found that pT stage was associated with both distant recurrence and decreased DFS and that LVI strongly correlated with $\mathrm{pT}$ stage and was associated with decreased DFS. This suggests that to mitigate the risk of distant recurrence and to improve survival, adjuvant therapy should be considered for appropriately selected patients, although the type and duration of such systemic treatment is not currently known.

In this study, pT stage, which is largely defined by tumor size, was associated with distant recurrence. Wu and colleagues ${ }^{18}$ found that tumor size was a predictor of all recurrence in patients with stage I NSCLC; however, that study did not directly evaluate distant recurrence but instead created a scoring system for various factors to evaluate the risk of distant recurrence. Large tumors $(3-5 \mathrm{~cm})$ were given higher weight in the scoring system, and overall, patients with high or intermediate risk scores had a higher risk of distant metastases compared with those with low risk scores $(P=.016) .{ }^{18}$ The role of adjuvant therapy for larger, node-negative tumors remains unclear. The Cancer and Leukemia Group B (CALGB) 9633 trial evaluated the benefit of adjuvant paclitaxel and carboplatin versus placebo after resection of pT2NOM0 NSCLC. ${ }^{19}$ The trial included all tumor histologic subtypes and found no difference in DFS or OS between groups. However, post hoc analysis suggested that patients with tumors $>4 \mathrm{~cm}$ treated with adjuvant chemotherapy experienced improved DFS and OS versus placebo. ${ }^{19}$ We found an association between both pT2a $(>3 \mathrm{~cm})$ and pT2b/3 $(>5 \mathrm{~cm})$ tumors and distant recurrence. Collectively, the findings of the CALGB 9633 study and our findings support that higher $\mathrm{pT}$ stage node-negative tumors are associated with a high incidence of distant recurrence. The current NCCN guidelines suggest that adjuvant chemotherapy should be considered for patients with high-risk factors, including tumor size $>4 \mathrm{~cm}$ (level 2A evidence). ${ }^{8}$

We also found a strong correlation between LVI and distant recurrence, an association between the presence of 

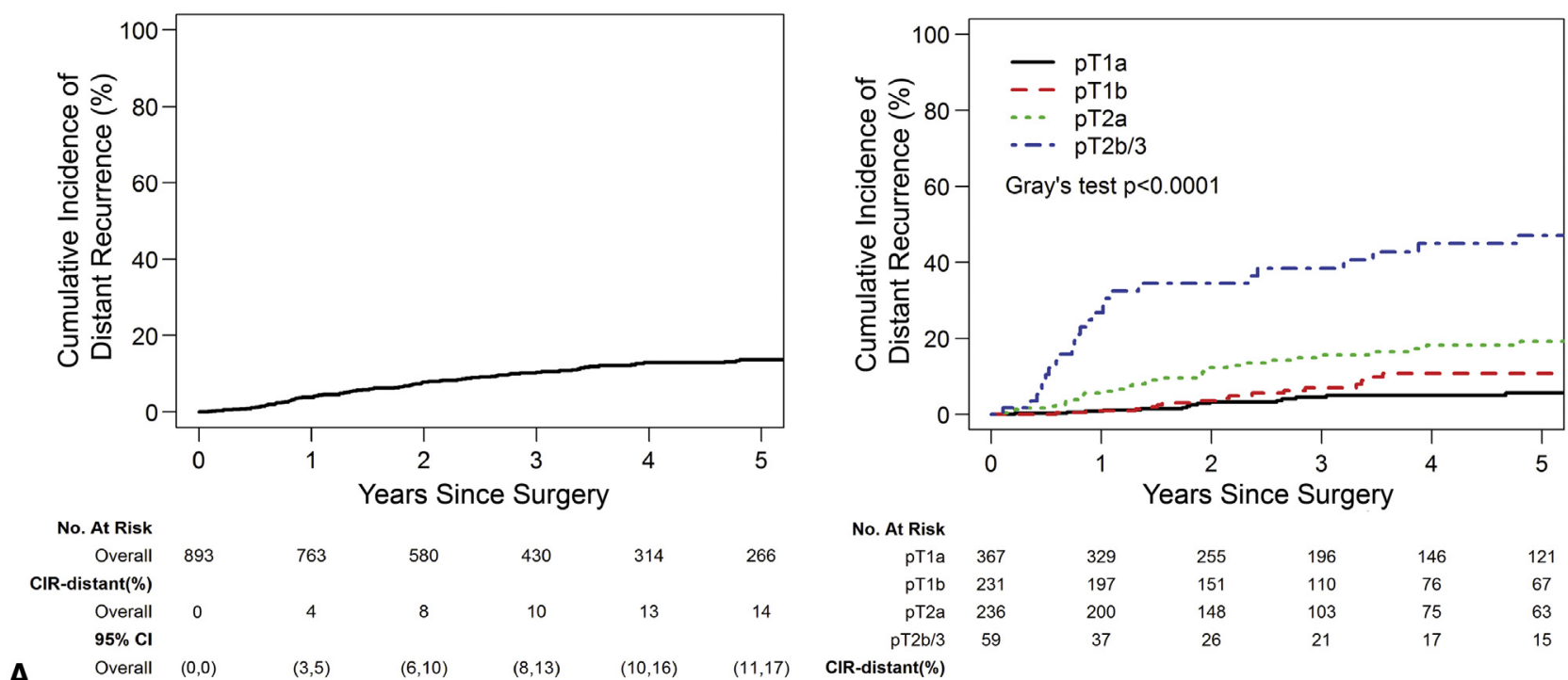
No. At Risk
pT1a 367
pT1b 23
PT2a 236
pT2b/3 59

$329 \quad 255$

197

$200-15$

151
148

$196 \quad 146$

110

103
21

76

R-distant(\%)

pT1a
pT1b

PT2a

pT2b/3 0

$95 \% \mathrm{Cl}$

pT1a $(0,0)$

pT1b $(0,0)$

pT2a $(0,0)$

B

$\begin{array}{ccccc}1 & 3 & 5 & 5 & 6 \\ 1 & 4 & 7 & 11 & 11 \\ 6 & 12 & 16 & 18 & 19 \\ 27 & 34 & 38 & 45 & 47 \\ & & & & \\ (0,3) & (2,6) & (3,8) & (3,8) & (3,9) \\ (0,4) & (2,8) & (4,12) & (7,18) & (7,18) \\ (3,10) & (9,18) & (11,22) & (13,25) & (14,26) \\ (17,41) & (24,50) & (27,54) & (33,61) & (35,63)\end{array}$

\begin{tabular}{|c|c|c|c|c|c|c|}
\hline \multicolumn{7}{|l|}{ No. At Risk } \\
\hline LVI Absent & 605 & 527 & 411 & 316 & 234 & 197 \\
\hline LVI Present & 273 & 225 & 158 & 106 & 73 & 63 \\
\hline \multicolumn{7}{|l|}{ CIR-distant(\%) } \\
\hline pT1a & 0 & 3 & 6 & 7 & 10 & 11 \\
\hline pT1b & 0 & 6 & 12 & 18 & 20 & 20 \\
\hline \multicolumn{7}{|l|}{$95 \% \mathrm{Cl}$} \\
\hline LVI Absent & $(0,0)$ & $(2,5)$ & $(4,8)$ & $(5,10)$ & $(7,13)$ & $(8,14)$ \\
\hline LVI Present & $(0,0)$ & $(4,10)$ & $(9,18)$ & $(13,24)$ & $(15,27)$ & $(15,27)$ \\
\hline
\end{tabular}

FIGURE 2. Cumulative incidence of distant recurrence (CIR-distant). (A) The CIR-distant for the entire cohort was $14 \%$ ( $95 \%$ confidence interval, $11 \%$ $17 \%$ ). (B and C) Five-year CIR-distant by pathologic tumor ( $p T)$ stage (B) and lymphovascular invasion (LVI) (C). CI, Confidence interval.

LVI and any recurrence, and decreased DFS in patients with LVI. However, in our complete case analysis, LVI was not associated with increased risk of recurrence. This discrepancy in findings may be due to the smaller sample size in the complete cohort, an overwhelming significance of $\mathrm{pT}$ stage that overshadows less dramatic associations, or a lack of true significance. Previous studies have demonstrated a relationship between LVI and recurrence. Kiankhooey and colleagues ${ }^{20}$ found that LVI was a predictor of any recurrence and multisite recurrence in 532 patients with stage IA to IIA NSCLC. In addition, a meta-analysis by Mollberg and colleagues ${ }^{21}$ of patients with stage I
NSCLC found that LVI was significantly associated with worse DFS $(P=.036)$ and OS $(P=.006)$. For tumors $>$ $4 \mathrm{~cm}$, the NCCN guidelines cite LVI as a "high-risk factor" that may be used to select patients for adjuvant therapy; however, the presence of isolated LVI is currently not an indication for adjuvant therapy (level $2 \mathrm{~A}$ evidence). ${ }^{8}$

Our group has led an effort to find associations between histologic subtype and outcomes in patients with lung adenocarcinoma. $^{22,23}$ In the present study, we found no association between micropapillary histologic subtype and recurrence on multivariable analysis (Tables 3 and E3). Previous studies have demonstrated that micropapillary 
TABLE 3. Variables associated with distant recurrence $(n=893)$

\begin{tabular}{|c|c|c|c|c|}
\hline \multirow[b]{2}{*}{ Variable } & \multicolumn{2}{|c|}{ Univariable analysis } & \multicolumn{2}{|c|}{ Multivariable analysis } \\
\hline & HR $(95 \%$ CI) & $P$ value & HR $(95 \%$ CI) & $P$ value \\
\hline Age & $1.01(0.99-1.03)$ & .234 & $1.01(0.98-1.03)$ & .611 \\
\hline Tumor $\mathrm{SUV}_{\max }$ & $1.10(1.06-1.14)$ & $<.001$ & $1.04(0.99-1.08)$ & .118 \\
\hline $\mathrm{FEV}_{1}$ & $1.00(0.99-1.01)$ & .454 & - & - \\
\hline DLCO & $0.99(0.98-1.00)$ & .246 & - & - \\
\hline \multicolumn{5}{|c|}{ Time of surgery (tertile) } \\
\hline $2000-2006$ & 1.00 & - & 1.00 & - \\
\hline $2007-2013$ & $0.64(0.41-0.99)$ & .045 & $0.67(0.41-1.10)$ & .113 \\
\hline 2014-2016 & $0.45(0.23-0.90)$ & .023 & $0.43(0.20-0.91)$ & .028 \\
\hline Tumor size, $\mathrm{cm}$ & $1.40(1.30-1.51)$ & $<.001$ & - & - \\
\hline \multicolumn{5}{|l|}{ Sex } \\
\hline Female & 1.00 & - & - & - \\
\hline Male & $1.37(0.92-2.03)$ & .121 & - & - \\
\hline \multicolumn{5}{|c|}{ Pulmonary comorbidity } \\
\hline No & 1.00 & - & - & - \\
\hline Yes & $0.87(0.54-1.39)$ & .554 & - & - \\
\hline \multicolumn{5}{|c|}{ Cardiac comorbidity } \\
\hline No & 1.00 & - & - & - \\
\hline Yes & $1.51(1.00-2.26)$ & .049 & - & - \\
\hline \multicolumn{5}{|l|}{ Histologic subtype } \\
\hline Lepidic & 1.00 & - & 1.00 & - \\
\hline Acinar & $2.58(0.82-8.09)$ & .104 & $1.82(0.58-5.66)$ & .301 \\
\hline Papillary & $2.59(0.63-10.5)$ & .185 & $1.67(0.45-6.20)$ & .444 \\
\hline Micropapillary & $6.12(1.63-23.0)$ & .007 & $3.16(0.81-12.3)$ & .099 \\
\hline Solid & $4.92(1.58-15.3)$ & .006 & $2.10(0.62-7.09)$ & .234 \\
\hline Other & $7.40(1.25-43.7)$ & .027 & $3.74(0.65-21.4)$ & .139 \\
\hline \multicolumn{5}{|c|}{ Visceral pleural invasion } \\
\hline Absent & 1.00 & - & - & - \\
\hline Present & $3.03(1.95-4.69)$ & $<.001$ & - & - \\
\hline \multicolumn{5}{|c|}{ Lymphovascular invasion } \\
\hline Absent & 1.00 & - & 1.00 & - \\
\hline Present & $2.11(1.41-3.15)$ & $<.001$ & $1.62(1.00-2.63)$ & .050 \\
\hline \multicolumn{5}{|l|}{ pT stage } \\
\hline $1 \mathrm{a}$ & 1.00 & - & 1.00 & - \\
\hline $1 b$ & $1.86(0.97-3.55)$ & .060 & $1.72(0.89-3.34)$ & .107 \\
\hline $2 \mathrm{a}$ & $3.71(2.10-6.54)$ & $<.001$ & $2.84(1.56-5.16)$ & .001 \\
\hline $2 b / 3$ & $11.0(5.80-20.8)$ & $<.001$ & $6.53(3.17-13.5)$ & $<.001$ \\
\hline \multicolumn{5}{|l|}{ EGFR mutation } \\
\hline No & 1.00 & - & - & - \\
\hline Yes & $0.61(0.26-1.44)$ & .257 & - & - \\
\hline \multicolumn{5}{|l|}{ KRAS mutation } \\
\hline No & 1.00 & & - & - \\
\hline Yes & $0.94(0.46-1.91)$ & .861 & - & - \\
\hline
\end{tabular}

$H R$, Hazard ratio; $C I$, confidence interval; $S U V_{\max }$, maximum standardized uptake value; $F E V_{l}$, forced expiratory volume in 1 second; $D L C O$, diffusion capacity of the lung for carbon monoxide.

subtype is associated with poor outcomes, including increased overall recurrence, decreased DFS, and decreased OS; however, very few studies have focused on the relationship between micropapillary subtype and distant recurrence. ${ }^{24,25}$ We have previously shown that patients with small $(<2 \mathrm{~cm})$ node-negative adenocarcinomas with a micropapillary-predominant histologic subtype who underwent sublobar resection had a higher rate of overall 


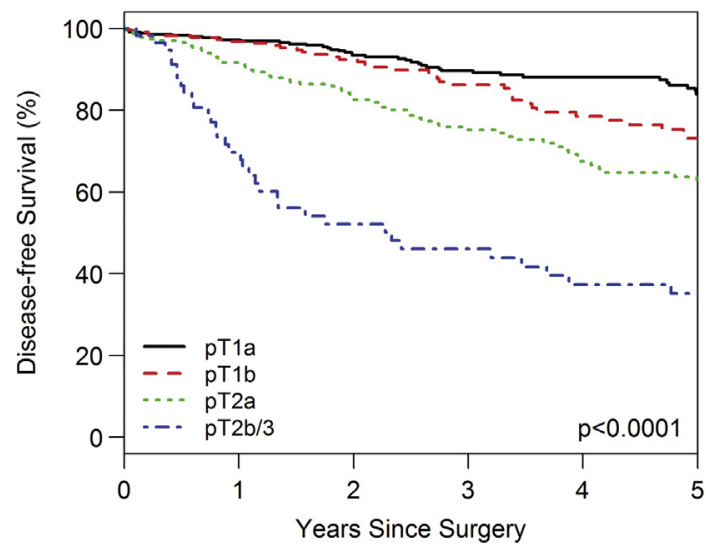

\begin{tabular}{|c|c|c|c|c|c|c|}
\hline \multirow{2}{*}{\multicolumn{7}{|c|}{ No. At Risk }} \\
\hline & & & & & & \\
\hline pT1a & 367 & 329 & 255 & 196 & 146 & 121 \\
\hline pT1b & 231 & 197 & 151 & 110 & 76 & 67 \\
\hline рт2a & 236 & 200 & 148 & 103 & 75 & 63 \\
\hline рT2b/3 & 59 & 37 & 26 & 21 & 17 & 15 \\
\hline \multicolumn{7}{|l|}{ DFS(\%) } \\
\hline pT1a & 100 & 97 & 93 & 90 & 88 & 84 \\
\hline pT1b & 100 & 97 & 92 & 86 & 79 & 73 \\
\hline рт2a & 100 & 92 & 83 & 75 & 68 & 63 \\
\hline $\mathrm{pT} 2 \mathrm{~b} / 3$ & 100 & 70 & 52 & 46 & 37 & 35 \\
\hline \multicolumn{7}{|l|}{$95 \% \mathrm{Cl}$} \\
\hline $\mathrm{pT} 1 \mathrm{a}$ & $(100,100)$ & $(95,99)$ & $(91,96)$ & $(86,93)$ & $(84,92)$ & $(79,89)$ \\
\hline pT1b & $(100,100)$ & $(95,99)$ & $(89,96)$ & $(81,92)$ & $(72,86)$ & $(66,82)$ \\
\hline pT2a & $(100,100)$ & $(88,95)$ & $(78,88)$ & $(69,82)$ & $(61,75)$ & $(55,71)$ \\
\hline $\mathrm{pT} 2 \mathrm{~b} / 3$ & $(100,100)$ & $(59,83)$ & $(40,67)$ & $(34,62)$ & $(26,53)$ & $(24,51)$ \\
\hline
\end{tabular}

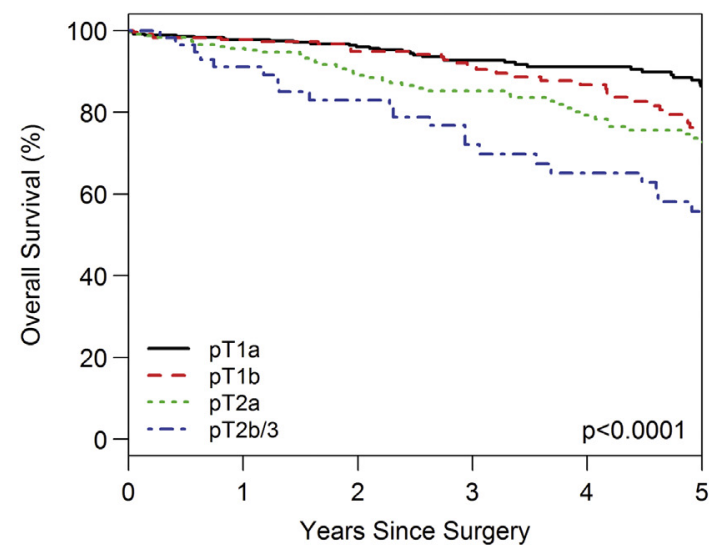

$\begin{array}{rrrrrrr}\text { No. At Risk } & & & & & \\ \text { pT1a } & 367 & 331 & 262 & 203 & 152 & 126 \\ \text { pT1b } & 231 & 199 & 156 & 118 & 87 & 71 \\ \text { PT2a } & 236 & 209 & 162 & 118 & 89 & 75 \\ \text { PT2b/3 } & 59 & 49 & 40 & 31 & 28 & 23 \\ \text { OS (\%) } & & & & & & \\ \text { PT1a } & 100 & 98 & 96 & 93 & 91 & 86 \\ \text { PT1b } & 100 & 98 & 95 & 91 & 87 & 76 \\ \text { PT2a } & 100 & 96 & 89 & 85 & 79 & 73 \\ \text { PT2b/3 } & 100 & 91 & 83 & 72 & 65 & 56 \\ 95 \% \text { Cl } & & & & & & \\ \text { PT1a } & (100,100) & (96,99) & (94,98) & (90,96) & (88,95) & (82,91) \\ \text { PT1b } & (100,100) & (96,100) & (92,98) & (87,96) & (81,93) & (69,85) \\ \text { pT2a } & (100,100) & (93,98) & (85,93) & (80,90) & (73,86) & (66,81) \\ \text { BT2b/3 } & (100,100) & (84,99) & (73,94) & (61,86) & (53,80) & (43,72)\end{array}$

FIGURE 3. Disease-free survival $(D F S)(\mathrm{A})$ and overall survival $(O S)$ (B) by pathologic tumor stage $(p T)$.

recurrence, particularly local recurrence. However, distant recurrence was not specifically evaluated, and micropapillary histologic subtype had no effect on recurrence in the lobectomy arm of the analysis. ${ }^{23}$ In addition, we found no association between solid histologic subtype and distant recurrence on multivariable analysis. We have previously reported that in patients with surgically resected small $(<2 \mathrm{~cm})$ lung adenocarcinoma, solid histologic subtype

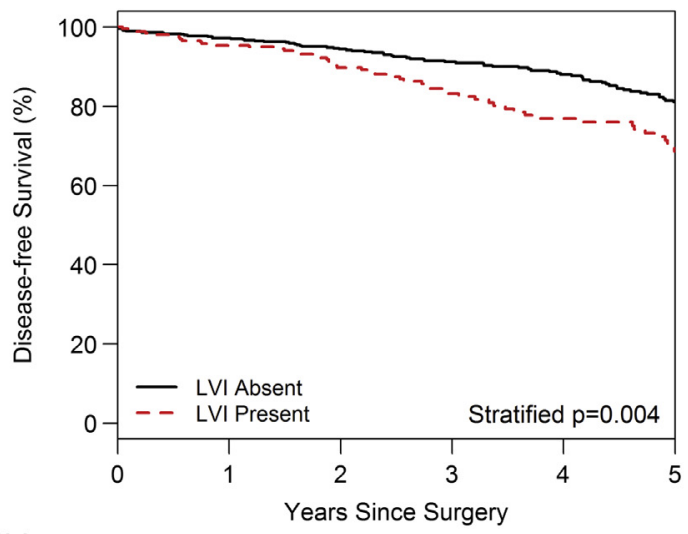

$\begin{array}{rcccccc}\begin{array}{r}\text { No. At Risk } \\ \text { LVI Absent }\end{array} & 605 & 540 & 429 & 335 & 258 & 215 \\ \text { LVI Present } & 273 & 236 & 180 & 126 & 90 & 73 \\ \text { DFS (\%) } & & & & & & \\ \text { LVI Absent } & 100 & 95 & 90 & 87 & 81 & 76 \\ \text { LVI Present } & 100 & 91 & 81 & 71 & 65 & 62 \\ 95 \% \text { CI } & & & & & & \\ \text { LVI Absent } & (100,100) & (93,97) & (88,93) & (84,90) & (77,85) & (72,81) \\ \text { LVI Present } & (100,100) & (88,95) & (76,86) & (65,78) & (59,73) & (54,70)\end{array}$

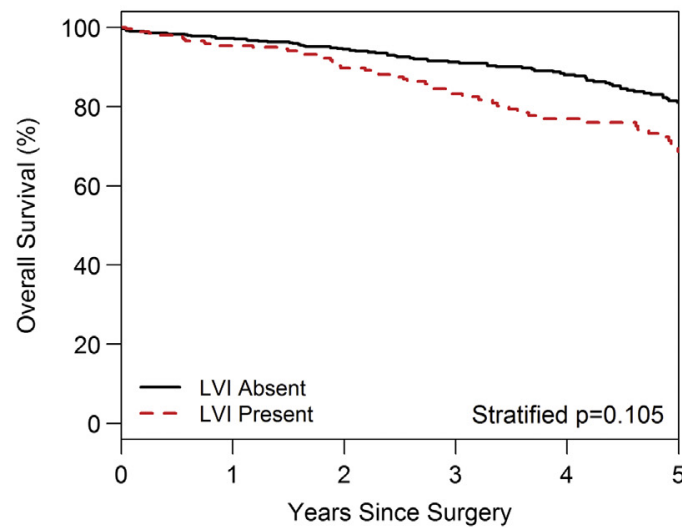

No. At Risk

$\begin{array}{lllllll}\text { LVI Absent } & 605 & 540 & 429 & 335 & 258 & 215\end{array}$ LVI Present

OS (\%)

LVI Absent

LVI Present

$95 \% \mathrm{Cl}$

540

$\begin{array}{llllll}100 & 97 & 94 & 91 & 88 & 81\end{array}$

100

95

LVI Absent $\quad(100,100)$

$\begin{array}{lllll}(96,99) & (93,96) \quad(89,94) \quad(85,91) \quad(77,85)\end{array}$

B LVI Present $(100,100) \quad(93,98) \quad(86,94) \quad(78,89) \quad(71,84) \quad(61,77)$

FIGURE 4. Disease-free survival (DFS) (A) and overall survival $(O S)(\mathrm{B})$ by the presence or absence of lymphovascular invasion $(L V I)$. $C I$, Confidence interval. 
was associated with earlier, extrathoracic, and multisite recurrence, particularly in sublobar resections. ${ }^{22,23}$ Our cohort differs in that $>50 \%$ of patients had tumors $>2 \mathrm{~cm}$ and all patients underwent lobectomy; nearly one-third of the patients in the aforementioned report underwent sublobar resection.

Although we found an association between tumor $\mathrm{SUV}_{\max }$ and distant recurrence on univariable analysis, this association did not remain significant on multivariable analysis. A review of the literature shows mixed results regarding an association between tumor $\mathrm{SUV}_{\max }$ and recurrence. ${ }^{20,26-28}$ Possible explanations for this lack of consensus include differences in the inclusion criteria for each study, varied tumor $\mathrm{SUV}_{\max }$ classification systems (categorical vs continuous variable), and variability of PET/CT scans across institutions.

In addition, we found that year of surgery, as expressed by tertile, was associated with distant recurrence on multivariable analysis-meaning that patients included in the early years of the study had a higher risk of recurrence than patients who underwent surgery more recently. Previous studies have demonstrated a $0.5 \%$ to $2 \%$ recurrence rate per year after 5 years, even in patients with stage IA NSCLC. ${ }^{29}$ This association in our study is likely due to both longer cumulative times to develop recurrence for patients in the earlier years of the study, as well as changes in clinical practice throughout the duration of our study.

Molecular genetics play an increasingly important role in pathological examination of tumors. The NCCN guidelines recommend routine molecular testing for EGFR (category 1), ALK (category 1), ROS1 (category 2A), $B R A F$ (category $2 \mathrm{~A}$ ), and $P D-L 1$ (category $2 \mathrm{~A}$ ) to help guide therapy. ${ }^{8}$ At our institution, we also perform Integrated Mutation Profiling of Actionable Cancer Targets (IMPACT) testing on nearly all of our primary cases of NSCLC to profile molecular aberrations and discover potential new molecular drivers. ${ }^{30}$ Here we evaluated 2 clinically relevant mutated genes in NSCLC (KRAS and $E G F R$ ). We found no significant associations between $E G F R$-activating or KRAS mutations and recurrence in our cohort. Izar and colleagues ${ }^{31}$ reported on 307 patients with resected stage IA lung adenocarcinoma (30\% sublobar resections) and found a lower recurrence rate for patients with an activating EGFR mutation compared with those with $E G F R$ wild-type tumors $(9.7 \%$ vs $21.6 \%$; $P=.03){ }^{31}$ In contrast, Kobayashi and colleagues ${ }^{32}$ examined 127 patients with p-stage IA lung adenocarcinoma who underwent lobectomy and found no association between EGFR mutation status and recurrence. Our group found no association between recurrence and EGFR mutation; however, we eliminated all patients who underwent sublobar resection and included patients with much larger tumors than in either of the aforementioned studies. In addition, EGFR mutation data $(\mathrm{n}=541)$ were not available for all patients: $37 \%$ of patients lacked these data, and these missing data may have affected our findings.

We also found no association between KRAS mutation and recurrence in our highly selected patient population. A review of the literature on the prognostic value of $K R A S$ in early-stage, node-negative lung cancer offers no clear answers. Izar and colleagues ${ }^{33}$ reported an association between KRAS mutation and worse survival in patients with stage I disease; however, a meta-analysis of 4 adjuvant chemotherapy trials $(\mathrm{n}=1543)$ found no association between KRAS mutation and OS or DFS. ${ }^{34}$ We recently examined the prognostic value of $K R A S$ mutation in patients with node-negative, p-stage I or II lung adenocarcinoma and found no association between KRAS mutation and risk of recurrence $(P=.29) .{ }^{35}$ A subset analysis by histologic subtype revealed an increased risk of overall recurrence for solid-predominant KRAS mutant tumors ( $12 \%$ of the entire cohort), but not for other histologic subtypes. ${ }^{35}$

The utility of targeted therapies for patients with pNO lung adenocarcinoma who are at high risk for distant recurrence has not been adequately studied. The Randomized Double-Blind Trial in Adjuvant NSCLC with Tarceva (RADIANT) trial evaluated adjuvant erlotinib therapy in patients with surgically resected stage IB to IIIA NSCLC with tumors expressing EGFR using immunohistochemical analysis ( $\geq 1 \%$ staining) or fluorescence in situ hybridization. ${ }^{10}$ DNA sequencing of the tumor to discern the presence of activating mutations was not performed. ${ }^{10}$ Not surprisingly, there was no difference in DFS or OS between the placebo and erlotinib arms. ${ }^{10}$ More recently, the Adjuvant Lung Cancer Enrichment Marker Identification and Sequencing Trials (ALCHEMIST) began accruing patients with stage IB-IIIA NSCLC and stratifies patients to receive adjuvant erlotinib (EGFR-activating mutations), crizotinib (ALK-EML4 rearrangements), or nivolumab (neither $E G F R$-activating nor $A L K$-EML4 rearrangement). ${ }^{36}$ The results of this study will help determine whether highly selected patient populations may benefit from adjuvant targeted therapies or immunotherapies, including those with earlier-stage lung cancers.

The limitations of this study include its retrospective, single-institution design, which may limit the generalizability of our findings. In addition, variances in preoperative staging approaches during the study period may have affected our results. For example, 63 patients $(7 \%)$ did not undergo a preoperative PET scan to rule out metastatic disease. However, only 2 of those patients had a distant recurrence, neither of which occurred before 24 months. This suggests that none of these patients had metastatic disease at the time of surgery. Another potential limitation is that this study extends across 16 years. Although our long-term follow-up is a strength, it also may be a limitation given the changes in treatment algorithms over time. For 
example, adjuvant chemotherapy has been increasingly used for larger, node-negative tumors. Therefore, more of these patients in the later years of our analysis may have been excluded, leading to an unintended selection bias. Finally, lack of a prospective, standardized intraoperative lymph node assessment protocol may have led to pathologic nodal understaging. However, the high OS of $78 \%$ in our entire cohort and the relatively similar $\mathrm{p}$ stage-specific results in the recent International Association for the Study of Lung Cancer studies suggest that this is unlikely. ${ }^{37}$

\section{CONCLUSIONS}

Our study demonstrates that pT stage and LVI are associated with distant recurrence in patients undergoing complete (R0) lobectomy for pN0 lung adenocarcinoma, without induction or adjuvant therapies. Distant recurrence rates remain very high $(19 \%-47 \%)$ for larger T-stage tumors, despite the use of an optimal surgical approach and node-negative disease. This study emphasizes the importance of actively accruing patients to current and future adjuvant therapy trials that examine the effect of targeted therapies and immunotherapies on decreasing distant recurrence.

\section{Webcast}

You can watch a Webcast of this AATS meeting presentation by going to: https://aats.blob.core.windows.net/media/ 17AM/2017-05-01/RM302-304/05-01-17_Room302-304_ 1555_Brandt.mp4.

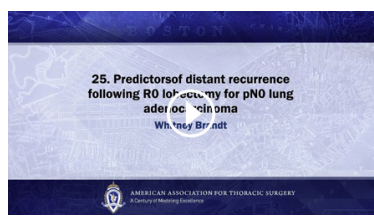

\section{Conflict of Interest Statement}

Authors have nothing to disclose with regard to commercial support.

\section{References}

1. Goldstraw P, Chansky K, Crowley J, Rami-Porta R, Asamura H, Eberhardt WE, et al. The IASLC Lung Cancer Staging Project: proposals for revision of the TNM stage groupings in the forthcoming (eighth) edition of the TNM classification for lung cancer. J Thorac Oncol. 2016;11:39-51.

2. Paul S, Isaacs AJ, Treasure T, Altorki NK, Sedrakyan A. Long-term survival with thoracoscopic versus open lobectomy: propensity matched comparative analysis using SEER-Medicare database. BMJ. 2014;349:g5575.

3. Hancock JG, Rosen JE, Antonicelli A, Moreno A, Kim AW, Detterbeck FC, et al. Impact of adjuvant treatment for microscopic residual disease after non-small cell lung cancer surgery. Ann Thorac Surg. 2015;99:406-13.

4. Ginsberg RJ, Rubinstein LV. Randomized trial of lobectomy versus limited resection for T1 N0 non-small cell lung cancer. Lung Cancer Study Group. Ann Thorac Surg. 1995;60:615-22; discussion 622-3.

5. Dai C, Shen J, Ren Y, Zhong S, Zheng H, He J, et al. Choice of surgical procedure for patients with non-small cell lung cancer $\leq 1 \mathrm{~cm}$ or $>1$ to $2 \mathrm{~cm}$ among lobec- tomy, segmentectomy, and wedge resection: a population-based study. J Clin Oncol. 2016:34:3175-82.

6. Detterbeck FC. Lobectomy versus limited resection in T1N0 lung cancer. Ann Thorac Surg. 2013;96:742-4.

7. Martini N, Melamed MR. Multiple primary lung cancers. J Thorac Cardiovasc Surg. 1975;70:606-12.

8. National Comprehensive Cancer Network. Clinical practice guidelines in oncology (NCCN guidelines): Non-small cell lung cancer. Version 2. April 25th, 2017. Available at: https://www.nccn.org/professionals/physician_gls/ default.aspx. Accessed May 11, 2017.

9. Kelsey CR, Higgins KA, Peterson BL, Chino JP, Marks LB, D’Amico TA, et al. Local recurrence after surgery for non-small cell lung cancer: a recursive partitioning analysis of multi-institutional data. J Thorac Cardiovasc Surg. 2013;146: 768-73.e1.

10. Kelly K, Altorki NK, Eberhardt WE, O'Brien ME, Spigel DR, Crinò L, et al Adjuvant erlotinib versus placebo in patients with stage IB-IIIA non-smallcell lung cancer (RADIANT): a randomized, double-blind, phase III trial. $J$ Clin Oncol. 2015;33:4007-14.

11. Travis WD, Brambilla E, Noguchi M, Nicholson AG, Geisinger KR, Yatabe Y, et al. International Association for the Study of Lung Cancer/American Thoracic Society/European Respiratory Society international multidisciplinary classification of lung adenocarcinoma. J Thorac Oncol. 2011;6:244-85.

12. van der Kruijk M. Multiple imputation with chained equations and survival outcomes: a simulation study [Master's thesis]. Department of Mathematics: Universiteit Leiden; 2015.

13. Rubin DB. Multiple imputation for nonresponse in surveys. New York: Wiley; 1987.

14. Fine JP. Regression modeling of competing crude failure probabilities. Biostatis tics. 2001;2:85-97.

15. Fine JP, Gray RJ. A proportional hazards model for the subdistribution of competing risk. J Am Stat Assoc. 1999;94:496-509.

16. Durrleman S, Simon R. Flexible regression models with cubic splines. Stat Med. 1989;8:551-61.

17. Zhou B, Fine J, Laird G. Goodness-of-fit test for proportional subdistribution hazards model. Stat Med. 2013;32:3804-11.

18. Wu CF, Fu JY, Yeh CJ, Liu YH, Hsieh MJ, Wu YC, et al. Recurrence risk factors analysis for stage I non-small cell lung cancer. Medicine (Baltimore). 2015;94: e1337.

19. Strauss GM, Herndon JE II, Maddaus MA, Johnstone DW, Johnson EA Harpole DH, et al. Adjuvant paclitaxel plus carboplatin compared with observation in stage IB non-small-cell lung cancer: CALGB 9633 with the Cancer and Leukemia Group B, Radiation Therapy Oncology Group, and North Central Cancer Treatment Group Study Groups. J Clin Oncol. 2008;26:5043-51.

20. Kiankhooy A, Taylor MD, LaPar DJ, Isbell JM, Lau CL, Kozower BD, et al. Predictors of early recurrence for node-negative T1 to T2b non-small cell lung cancer. Ann Thorac Surg. 2014;98:1175-83.

21. Mollberg NM, Bennette C, Howell E, Backhus L, Devine B, Ferguson MK. Lymphovascular invasion as a prognostic indicator in stage I non-small cell lung cancer: a systematic review and meta-analysis. Ann Thorac Surg. 2014;97:965-71.

22. Ujiie H, Kadota K, Chaft JE, Buitrago D, Sima CS, Lee MC, et al. Solid predominant histologic subtype in resected stage I lung adenocarcinoma is an independent predictor of early, extrathoracic, multisite recurrence and of poor postrecurrence survival. J Clin Oncol. 2015;33:2877-84.

23. Nitadori J, Bograd AJ, Kadota K, Sima CS, Rizk NP, Morales EA, et al Impact of micropapillary histologic subtype in selecting limited resection vs lobectomy for lung adenocarcinoma of $2 \mathrm{~cm}$ or smaller. J Natl Cancer Inst. 2013;105:1212-20.

24. Zhang F, Zheng W, Ying L, Wu J, Wu S, Ma S, et al. A nomogram to predict brain metastases of resected non-small cell lung cancer patients. Ann Surg Oncol. 2016;23:3033-9.

25. Yoshida Y, Nitadori JI, Shinozaki-Ushiku A, Sato J, Miyaji T, Yamaguchi T, et al Micropapillary histological subtype in lung adenocarcinoma of $2 \mathrm{~cm}$ or less: impact on recurrence and clinical predictors. Gen Thorac Cardiovasc Surg. 2017;65:273-9.

26. Taylor MD, Nagji AS, Bhamidipati CM, Theodosakis N, Kozower BD, Lau CL, et al. Tumor recurrence after complete resection for non-small cell lung cancer. Ann Thorac Surg. 2012;93:1813-20; discussion 1820-1.

27. Yang HC, Kim HR, Jheon S, Kim K, Cho S, Ahn S, et al. Recurrence risk-scoring model for stage I adenocarcinoma of the lung. Ann Surg Oncol. 2015;22:4089-97.

28. Shiono S, Abiko M, Okazaki T, Chiba M, Yabuki H, Sato T. Positron emission tomography for predicting recurrence in stage I lung adenocarcinoma: 
standardized uptake value corrected by mean liver standardized uptake value. Eur J Cardiothorac Surg. 2011;40:1165-9.

29. Maeda R, Yoshida J, Hishida T, Aokage K, Nishimura M, Nishiwaki Y, et al. Late recurrence of non-small cell lung cancer more than 5 years after complete resection: incidence and clinical implications in patient follow-up. Chest. 2010;138: 145-50.

30. Cheng DT, Mitchell TN, Zehir A, Shah RH, Benayed R, Syed A, et al. Memorial Sloan Kettering-Integrated Mutation Profiling of Actionable Cancer Targets (MSK-IMPACT): a hybridization capture-based next-generation sequencing clinical assay for solid tumor molecular oncology. J Mol Diagn. 2015;17:251-64.

31. Izar B, Sequist L, Lee M, Muzikansky A, Heist R, Iafrate J, et al. The impact of EGFR mutation status on outcomes in patients with resected stage I non-small cell lung cancers. Ann Thorac Surg. 2013;96:962-8.

32. Kobayashi N, Toyooka S, Ichimura K, Soh J, Yamamoto H, Matsuo K, et al. NonBAC component, but not epidermal growth factor receptor gene mutation is associated with poor outcomes in small adenocarcinoma of the lung. J Thorac Oncol. 2008;3:704-10.

33. Izar B, Zhou H, Heist RS, Azzoli CG, Muzikansky A, Scribner EE, et al. The prognostic impact of KRAS, its codon and amino acid specific mutations, on survival in resected stage I lung adenocarcinoma. J Thorac Oncol. 2014;9:1363-9.

34. Shepherd FA, Domerg C, Hainaut P, Jänne PA, Pignon JP, Graziano S, et al. Pooled analysis of the prognostic and predictive effects of KRAS mutation status and KRAS mutation subtype in early-stage resected non-small-cell lung cancer in four trials of adjuvant chemotherapy. J Clin Oncol. 2013;31:2173-81.

35. Kadota K, Sima C, Arcila ME, Hedvat C, Kris MG, Jones DR, et al. KRAS mutation is a significant prognostic factor in early-stage lung adenocarcinoma. Am J Surg Pathol. 2016;40:1579-90.

36. National Cancer Institute. The ALCHEMIST Lung Cancer Trials. 2016. Available at: https://www.cancer.gov/types/lung/research/alchemist. April 25, 2017. Accessed May 11, 2017.

37. Rami-Porta R, Bolejack V, Crowley J, Ball D, Kim J, Lyons G, et al. The IASLC Lung Cancer Staging Project: proposals for the revisions of the T descriptors in the forthcoming eighth edition of the TNM classification for lung cancer. J Thorac Oncol. 2015;10:990-1003.

Key Words: lobectomy, lung adenocarcinoma, pathologic tumor stage, lymphovascular invasion, recurrence

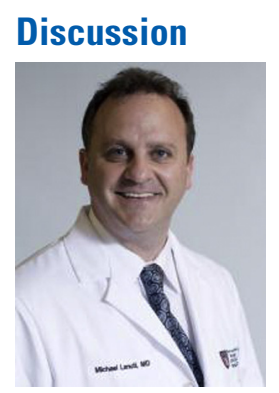

Dr Michael Lanuti (Boston, Mass). Dr Brandt, congratulations on a wellpresented study and good recovery there with your manuscript and your coauthors from Memorial. I just want to highlight a few things just in case they went by you.

This is a node-negative analysis of tumors that were T1, T2, T3 up to $9 \mathrm{~cm}$. And so the findings overall, I would say that with regard to predictors of recurrence $\mathrm{T}$ stage, are pretty intuitive; the higher $\mathrm{T}$ stage the more likely you are going to recur. So this corroborated lymphovascular invasion. You didn't mention the year of surgery, which we will talk about.

The analysis of this cohort is over 16 years, and that is otherwise challenging. The accumulation of patients during this time contributed to statistical power, but as the authors have recognized, the analysis over that long time period is subject to changes in treatment and staging modalities and the use of PET and, in fact, invasive mediastinal staging. So this is probably most appreciated in the patients who had stage IIA and IIB disease; I think there were about 52 of them. So those patients, in about 2006 after the International Adjuvant Lung Cancer Trial, would receive adjuvant therapy. So essentially, if you were to remove them from your cohort, they would enhance the fact that there would be less recurrence.

One thing that I had thought about was, have you considered excluding those high-risk patients from the analysis to focus on the risk of, let's say, smaller or stage IA and B disease?

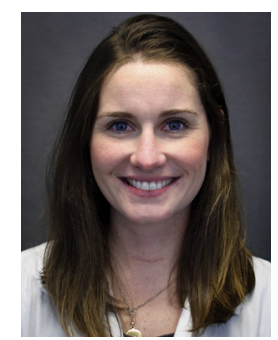

Dr Whitney Brandt (New York, NY). This is a good point. We recognize that patients with $\mathrm{pT} 2 \mathrm{~b}$ or 3 tumors have a known decrease in survival compared to those with lesser pT disease. But one of the goals of our study was to estimate the actual risk of distant recurrence in patients with larger tumors even though they were still node-negative, and I think that finding that $50 \%$ of patients with node-negative disease and larger tumors and assigning a number to it is helpful for the population. But, yes, it doesn't make it as clean with them.

Dr Lanuti. Another observation was that in your list of recurrences there were about 42 recurrences that were in the lung. So how were you able to reconcile whether those were actually metachronous lung cancers or really metastatic disease when you were doing your analysis?

Dr Brandt. We used, as I mentioned, the criteria put forth by Martini, and part of that was using histology, histologic subtype patterns, and then tumor genomic data when available.

Dr Lanuti. My next question has to do with what you didn't mention here, that the year of surgery was significant in the manuscript. So can you better explain what you mean by year of surgery as a risk of recurrence? Do you mean that the risk of recurrence in any single patient was higher at year $1,2,3,4$, and 5, or do you mean that all patients treated in a particular year, let's say 2004, had a different risk compared to those that recurred in 2001? What is the reason, improved selection, staging of more contemporary patients is better? What do you reconcile the reason is?

Dr Brandt. To answer the first part of your question, it has to do with the actual year of surgery. So all the patients in, for example, 2016 had a lesser chance of developing recurrence than patients that were included in 2000. And part of what we thought as the reason behind that is in part due to what you said about patients that were included later years in the study with larger tumors were more likely to probably get adjuvant therapy and therefore be excluded from the study. So there might be a little bit of selection bias, but the larger part might be in fact due to patients in more recent years have had less time to follow up and therefore they 
might recur if they had longer time to follow-up in case we did this study 5 years later and ended at 2016, and maybe those patients would have developed distant recurrence.

Dr Lanuti. My last question is with regard to genotyping, because as the audience hopefully recognized, this is all lung adenocarcinoma, and the reason was that you were looking for genotyping, which would be done strictly on adenocarcinomas, and so the squamous cells, which were about 800 or so, or other histologies were excluded. And you mentioned that there was no risk with regards to an $E G F R$ mutation versus wild type in a node negative resected lung cancer. I am surprised you didn't capture a signal, because in our own work, and we just updated this with 700 patients who were resected lobectomies node-negative, if you were an EGFR mutant, you were protected against recurrence with a hazard ratio of about .4, these are chemonaive patients, as opposed to a wild type where you had more recurrence. I'm curious that you didn't pick up a signal. Can you comment on that?

Dr Brandt. I looked at your previous paper, not the most recent one with 700 patients but the one with about 350 patients, and it is interesting that we did find different results between our study and yours. I have a couple of reasons, but maybe due to the selection differences in our papers. In your first paper with 350 patients, about $40 \%$ of patients had sublobar resection, and in our study, as I highlighted, our median tumor size was $2.2 \mathrm{~cm}$, with a range from .2 to $9 \mathrm{~cm}$, and your study was smaller tumors. This could be due to a difference in size or the resection itself.

Dr Lanuti. I congratulate the authors on expanding the literature on recurrence of stage I. This is a place where surgeons have a particular influence because this is what we treat.

Dr Brandt. Thank you.

Dr Seth Krantz (Evanston, Ill). That was a great talk. I really appreciate it. The point about adjuvant therapy is very interesting. My question, though, is how were most of these patients with distant recurrence found? I don't know if I missed that, but I saw 5\% of T1 patients and $16 \%$ of $\mathrm{T} 2$ patients who when I follow these patients who aren't getting adjuvant therapy are getting serial CT scans of the chest and that will catch the adrenals. Were these patients being found on just routine follow-up CT scans, were they symptomatic? At a $16 \%$ distant recurrence rate, does that maybe imply we should be following these patients differently than just a chest CT when they are failing distantly as opposed to locally?

Dr Brandt. All of our patients were followed up according to the NCCN guidelines. So for the first 2 to 3 years they had a history and physical and then a CAT scan every 6 months and then after that annually. Some patients were found on those CAT scans and some PET CT's if they were done for any reason, and $86 \%$ of those were confirmed by pathology when found.

Dr Krantz. Do you know, were most of the recurrences found on surveillance or were patients symptomatic?

Dr Brandt. I don't have that data, but that is an interesting point.

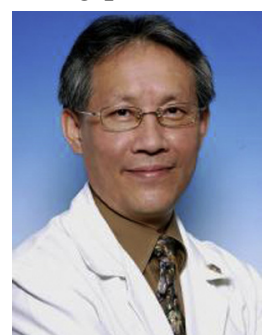

Dr Ching Tzao (Taipei, Taiwan). Congratulations on this wonderful presentation and paper. I have a question. When you set out all these parameters or the predictors, is there any particular reason that you exclude metabolic predictors, like PET scan, the SUV? Those are extensively investigated in previous reports. And the second thing is the visceral pleural invasions; is there any particular reason that you exclude this risk factor from your study, because those are conventionally believed important risk factors? That's question one.

And the second, based on your result, do you think if patients carry high risk factors, would that alter the way you follow the patients?

And in the final conclusion, you said that adjuvant therapy might be needed. How do you propose a working model to validate these things?

Dr Brandt. The first question was about whether SUV primary and visceral pleural invasion were evaluated. We did look at SUV primary. It was significant on univariable analysis, but when we looked at multivariable analysis it fell out. In part, we were thinking that might be highly associated with tumor size.

We also looked at visceral pleural invasion. In univariable, it was significant, and it also fell out in multivariable, and which we found was highly associated with pT stage and that's why.

Your second question?

Dr Tzao. The patients with high risk factors from your study, would that alter the way you follow the patients?

Dr Brandt. I am not sure about the way we follow the patients, but I think what we really need are nomograms that say if you have lymphovascular invasion and a higher $\mathrm{pT}$ stage, what is your risk of recurrence, and that should possibly drive giving adjuvant therapy, and we don't know specifically if chemotherapy is better or targeted therapies may be the way to go.

Right now Memorial is enrolling patients in the ALCHEMIST trials, which take patients with EGFR mutations and give those patient erlotinib, there is a second arm with patients with $A L K$ rearrangements who get crizotinib, and a third arm without either of those mutations who get nivolumab. So that might help kind of sort out whether or not these patients would benefit from adjuvant therapy. 
Dr Tzao. The other thing I am curious about is the lymph node dissection. Some of the results may be biased by the underestimation by less lymph node dissection. Is that a possible factor for distant recurrence in the future? Did you look into that?

Dr Brandt. We looked into that and we evaluated how many patients got appropriate lymph node staging, because that is definitely a possibility if they were understaged. We think that probably is not the case, and that is partially because our overall survival is very similar to that which is reported in the literature and it is very good. So we think that most patients were probably staged appropriately, although it is still a possibility. 
TABLE E1. Clinicopathologic characteristics of complete case cohort $(\mathrm{n}=622)$

\begin{tabular}{lc}
\hline \multicolumn{1}{c}{ Characteristic } & Value \\
\hline Age, $\mathrm{y}$, median (range) & $72(36-92)$ \\
Sex, $\mathrm{n}(\%)$ & \\
Female & $398(64)$ \\
Male & $224(36)$ \\
Time of surgery (tertile), $\mathrm{n}(\%)$ & \\
2000-2006 & $156(25)$ \\
2007-2013 & $240(39)$ \\
2014-2016 & $226(36)$ \\
Tumor characteristics, median (range) & \\
Tumor SUV $\mathrm{V}_{\text {max }}(\mathrm{n}=721)$ & $3.4(0.5-9.8)$ \\
Tumor size (cm) & $2.2(0.6-9.0)$ \\
Predominant histologic subtype $(\mathrm{n}=765), \mathrm{n}(\%)$ & \\
Lepidic & $89(14)$ \\
Acinar & $294(47)$ \\
Papillary & $113(18)$ \\
Micropapillary & $23(3.7)$ \\
Solid & $92(15)$ \\
Other & $11(1.8)$ \\
Lymphovascular invasion $(\mathrm{n}=878), \mathrm{n}(\%)$ & $217(35)$ \\
pT stage, $\mathrm{n}(\%)$ & \\
1a & \\
1b & $242(39)$ \\
2a & $158(25)$ \\
2b/3 & $180(29)$ \\
\hline$S U V_{\text {max }}$, Maximum standardized uptake value; $p T$, pathologic stage. \\
\end{tabular}


TABLE E2. Multivariable complete case analysis $(n=622)$

\begin{tabular}{|c|c|c|c|c|}
\hline \multirow[b]{2}{*}{ Variable } & \multicolumn{2}{|c|}{ Distant recurrence } & \multicolumn{2}{|c|}{ Any recurrence } \\
\hline & HR $(95 \%$ CI) & $P$ value & HR $(95 \%$ CI) & $P$ value \\
\hline Age & $1.01(0.99-1.04)$ & .326 & $1.02(0.99-1.04)$ & .215 \\
\hline Tumor $\mathrm{SUV}_{\max }$ & $1.04(0.99-1.10)$ & .107 & $1.04(0.98-1.09)$ & .177 \\
\hline \multicolumn{5}{|c|}{ Time of surgery (tertile) } \\
\hline $2000-2006$ & 1.00 & - & 1.00 & - \\
\hline 2007-2013 & $0.68(0.38-1.24)$ & .212 & $0.71(0.40-1.25)$ & .235 \\
\hline 2014-2016 & $0.46(0.19-1.08)$ & .074 & $0.46(0.20-1.05)$ & .065 \\
\hline \multicolumn{5}{|l|}{ Histologic subtype } \\
\hline Lepidic & 1.00 & - & 1.00 & - \\
\hline Acinar & $2.11(0.63-7.07)$ & .228 & $1.48(0.53-4.15)$ & .453 \\
\hline Papillary & $1.95(0.53-7.25)$ & .317 & $1.76(0.58-5.31)$ & .317 \\
\hline Micropapillary & $4.48(1.06-19.0)$ & .042 & $3.38(0.97-11.7)$ & .056 \\
\hline Solid & $3.20(0.88-11.6)$ & .078 & $2.18(0.70-6.84)$ & .180 \\
\hline Other & $4.70(0.84-26.4)$ & .079 & $2.91(0.57-14.9)$ & .201 \\
\hline \multicolumn{5}{|c|}{ Lymphovascular invasion } \\
\hline Absent & 1.00 & - & 1.00 & - \\
\hline Present & $1.26(0.71-2.27)$ & .432 & $1.49(0.86-2.58)$ & .154 \\
\hline \multicolumn{5}{|l|}{ pT stage } \\
\hline $1 \mathrm{a}$ & 1.00 & 一 & 1.00 & - \\
\hline $1 b$ & $2.07(0.91-4.72)$ & .084 & $2.13(0.98-4.61)$ & .055 \\
\hline $2 \mathrm{a}$ & $3.25(1.55-6.83)$ & .002 & $3.25(1.60-6.58)$ & .001 \\
\hline $2 b / 3$ & $6.43(2.40-17.3)$ & $<.001$ & $7.86(3.09-20.0)$ & $<.001$ \\
\hline
\end{tabular}

$H R$, Hazard ratio; $C I$, confidence interval; $S U V_{\max }$, maximum standardized uptake value; $p T$, pathologic tumor. 
TABLE E3. Variables associated with any recurrence $(n=893)$

\begin{tabular}{|c|c|c|c|c|}
\hline \multirow[b]{2}{*}{ Variable } & \multicolumn{2}{|c|}{ Univariable } & \multicolumn{2}{|c|}{ Multivariable } \\
\hline & HR $(95 \%$ CI $)$ & $P$ value & HR $(95 \%$ CI) & $P$ value \\
\hline Age & $1.01(0.99-1.03)$ & .222 & $1.01(0.98-1.03)$ & .614 \\
\hline Tumor $\mathrm{SUV}_{\max }$ & $1.09(1.06-1.13)$ & $<.001$ & $1.03(0.99-1.08)$ & .173 \\
\hline $\mathrm{FEV}_{1}$ & $0.99(0.99-1.00)$ & .200 & - & - \\
\hline DLCO & $0.99(0.98-1.00)$ & .144 & - & - \\
\hline \multicolumn{5}{|c|}{ Time of surgery (tertile) } \\
\hline $2000-2006$ & 1.00 & 一 & 1.00 & - \\
\hline 2007-2013 & $0.65(0.43-0.97)$ & .037 & $0.67(0.42-1.07)$ & .094 \\
\hline 2014-2016 & $0.46(0.24-0.87)$ & .018 & $0.41(0.20-0.86)$ & .018 \\
\hline Tumor size $(\mathrm{cm})$ & $1.42(1.31-1.53)$ & $<.001$ & - & - \\
\hline \multicolumn{5}{|l|}{ Sex } \\
\hline Female & 1.00 & - & - & - \\
\hline Male & $1.26(0.87-1.82)$ & .223 & - & - \\
\hline \multicolumn{5}{|c|}{ Pulmonary comorbidity } \\
\hline No & 1.00 & - & - & - \\
\hline Yes & $0.84(0.54-1.31)$ & .443 & - & - \\
\hline \multicolumn{5}{|c|}{ Cardiac comorbidity } \\
\hline No & 1.00 & - & - & - \\
\hline Yes & $1.39(0.96-2.02)$ & .084 & - & - \\
\hline \multicolumn{5}{|l|}{ Histologic subtype } \\
\hline Lepidic & 1.00 & - & 1.00 & - \\
\hline Acinar & $2.10(0.73-6.02)$ & .166 & $1.41(0.50-4.02)$ & .517 \\
\hline Papillary & $2.71(0.77-9.53)$ & .119 & $1.71(0.53-5.51)$ & .367 \\
\hline Micropapillary & $6.39(1.90-21.5)$ & .003 & $3.34(0.97-11.5)$ & .057 \\
\hline Solid & $4.20(1.46-12.1)$ & .008 & $1.74(0.52-5.75)$ & .366 \\
\hline Other & $6.43(1.02-40.7)$ & .048 & $3.27(0.48-22.1)$ & .225 \\
\hline \multicolumn{5}{|c|}{ Visceral pleural invasion } \\
\hline Absent & 1.00 & - & - & - \\
\hline Present & $2.59(1.70-3.96)$ & $<.001$ & - & - \\
\hline \multicolumn{5}{|c|}{ Lymphovascular invasion } \\
\hline Absent & 1.00 & - & 1.00 & - \\
\hline Present & $2.15(1.48-3.12)$ & $<.001$ & $1.66(1.06-2.60)$ & .026 \\
\hline \multicolumn{5}{|l|}{ pT stage } \\
\hline 1a & 1.00 & 一 & 1.00 & - \\
\hline $1 b$ & $1.95(1.08-3.52)$ & .027 & $1.76(0.96-3.22)$ & .066 \\
\hline $2 \mathrm{a}$ & $3.75(2.23-6.32)$ & $<.001$ & $2.94(1.70-5.07)$ & $<.001$ \\
\hline $2 b / 3$ & $11.2(6.14-20.5)$ & $<.001$ & $6.73(3.44-13.2)$ & $<.001$ \\
\hline$E G F R$ mutation & & & - & - \\
\hline No & 1.00 & - & - & - \\
\hline Yes & $0.74(0.35-1.56)$ & .428 & - & - \\
\hline$K R A S$ mutation & & & - & - \\
\hline No & 1.00 & - & & \\
\hline Yes & $0.77(0.38-1.53)$ & .450 & - & - \\
\hline
\end{tabular}

$H R$, Hazard ratio; $C I$, confidence interval; $S U V_{\max }$, maximum standardized uptake value; $F E V_{l}$, forced expiratory volume in 1 second; $D L C O$, diffusion capacity of the lung for carbon monoxide; $p T$, pathologic tumor. 